that paracetamol could be used as an alternative for infants who are either ibuprofen-resistant or for whom ibuprofen is contraindicated. Further prospective randomized-controlled trials are needed to evaluate the efficacy of paracetamol for the closure of PDA.

\section{THE EFFECT OF HEPARIN INFUSION ON DEVELOPMENT OF THROMBOSIS SECONDARY TO CARDIAC CATHETERIZATION}

doi:10.1136/archdischild-2012-302724.1122

'S Erol, ' ${ }^{2} \mathrm{G}$ Çınar, ${ }^{3} \mathrm{U} A$ Örün, 'B Aydın, 'D Dilli, 'A Dursun, 'S Beken, 'A Zenciroğlu, ${ }^{1} \mathrm{~N}$ Okumuş, ${ }^{3} \mathrm{~S}$ Karademir. ${ }^{1}$ Neonatology; ${ }^{2}$ Radiology; ${ }^{3}$ Pediatric Cardiology, Dr Sami Ulus Maternity and Children's Health and Diseases Training and Research Hospital, Ankara, Turkey

Background and Aim Cardiac catheterization is an important diagnostic tool. In this study, the frequency and the factors affecting the development of thrombosis were prospectively evaluated in neonates who were subjected to diagnostic and interventional cardiac catheterization.

Method 29 patients were enrolled in this study. Blood samples were taken for complete blood count, prothrombin, activated partial thromboplastin time, INR ratio, mutation of factor $V$ Leiden, prothrombin 20210 A, MTHFR C667 and A1298 before the procedure. $50 \mathrm{U} / \mathrm{kg}$ bolus of heparin was infused during catheterization and $20 \mathrm{U} / \mathrm{kg} /$ hour infusion of heparin was given to patients with clinically suspected thrombosis. Doppler was performed in all patients within 6 hours after catheterization.

Results Arterial catheterization in 16 cases, venous catheterization in 7 cases and both were applied in 6 cases. Arterial thrombosis in 7 patients and venous thrombosis in two patients was detected. It's observed that infusion of $20 \mathrm{U} / \mathrm{kg} / \mathrm{h}$ heparin had no effect on the development of arterial thrombosis. On the development of arterial and venous thrombosis, patient age, gender, diagnosis, treatments received prior to catheterization, hemoglobin and platelet count, PT, aPTT and INR values and Factor V Leiden, prothrombin $20210 \mathrm{~A}$, MTHFR C667, A1298 mutations were found as not impacting.

Conclusion There are no exact protocols for the prevention of thrombosis during and after catheterization. In this study, $50 \mathrm{unit} / \mathrm{kg}$ heparine bolus during catheterization and 20 unit $/ \mathrm{kg} /$ hour heparine infusion after catheterization did not prevent the development of thrombosis. Extensive studies are needed to determine the appropriate drugs and/or doses of preventive treatments.

\section{DO PATENT DUCTUS ARTERIOSUS AND ITS TREATMENT WITH ORAL IBUPROFEN AFFECT RENAL AND MESENTERIC TISSUE OXYGENATION IN PRETERM INFANTS?}

doi:10.1136/archdischild-2012-302724.1123

${ }^{1} \mathrm{~N}$ Guzoglu, 'FN Sari, 'R Ozdemir, 'S Oguz, 'N Uras, ${ }^{2} \mathrm{~N}$ Altug, 'U Dilmen. 'Neonatology; 2Pediatric Cardiology, Zekai Tahir Burak Maternity and Teaching Hospital, Ankara, Turkey

Background/Aim Patent ductus arteriosus (PDA) in preterm infants can result in serious hemodynamic changes causing respiratory, gastrointestinal and renal morbidities if not treated within the first week of life. We investigated the impact of PDA and its treatment with oral ibuprofen on regional renal and mesenteric oxygen saturation.

Methods 13 infants with PDA (gestational age $<32$ weeks), subsequently treated with oral ibuprofen, were monitored for mean arterial blood pressure, arterial oxygen saturation, near-infrared spectroscopy-determined regional renal and mesenteric oxygen saturation. The patients with PDA were matched for gestational age, birth weight, postnatal age, and severity of respiratory distress syndrome with infants without PDA, who served as control subjects.

Results Median renal and mesenteric oxygen saturation were similar in infants with PDA before and up to 12 hours after the start of ibuprofen therapy [renal oxygen saturation: $50 \%$ (25th-75th percentile: $29.5-65.5 \%$ ) vs. $54 \%$ (25th-75th percentile: $36-72.5 \%$ ), $\mathrm{p}=0.556$; respectively); mesenteric oxygen saturation: $31 \%$ (25th-75th percentile: $19-38 \%$ ) vs. $32 \%$ (25th-75th percentile: $23.5-46 \%$ ), $p=0.239$; respectively]. Median renal and mesenteric oxygen saturation in control infants were also not significantly different in infants with PDA before and up to 12 hours after the start of ibuprofen therapy.

Conclusions A hemodynamically significant PDA and its adequate treatment with oral ibuprofen seem not to affect the renal and mesenteric perfusion and subsequent oxygen delivery in very low birth weight preterm infants.

\section{LEVOSIMENDAN RESCUE THERAPY IN NON- CARDIOSURGICAL NEONATES WITH HEART FAILURE: A CASE SERIES}

doi:10.1136/archdischild-2012-302724.1124

${ }^{1} \mathrm{~A}$ Tempera, ${ }^{2 \mathrm{M}}$ Piastra, ${ }^{2} \mathrm{E}$ Luca, ${ }^{3} \mathrm{G}$ De Rosa, ${ }^{1} \mathrm{E}$ Buffone, ${ }^{2} \mathrm{G}$ Conti, ${ }^{4} \mathrm{MP}$ De Carolis. ${ }^{1}$ Neonatal ICU, S.Camillo-Forlanini Hospital; ' $E$ Emergency Department, Pediatric ICU, ${ }^{3}$ Pediatric Cardiology, Department of Pediatrics; ${ }^{4}$ Neonatal ICU, Department of Pediatrics, Catholic University of the Sacred Heart, A. Gemelli Hospital, Roma, Italy

Background and Aims To report the successful use of the new inodilator levosimendan in 4 critically ill neonates with refractory heart failure. At present, no data are available on the use of levosimendan in newborns outside the cardiosurgical setting.

Methods Clinical chart review.

Results Neonates described in Table 1 were given LS due to severe refractory heart failure when standard treatment was ineffective and/or complications occurred. LS was administered as a continuous i.v. infusion $(0.2 \mathrm{mcg} / \mathrm{kg} / \mathrm{min}$ over the first $24 \mathrm{hrs})$. LS addition resulted in an improvement and/or stabilisation of hemodynamic status, with nearly normal restoration of heart function in $2 / 4$ infants. Patients with $\mathrm{PH}$ and RV enlargement could be weaned off from pulmonary vasodilators.

Conclusions In these full-term neonates with post-ischaemic low cardiac output/pulmonary hypertension and heart failure of infectious or metabolic origin, refractory to first line inotropic drugs, LS was a potent inotropic agent and a possible add-on therapy. As suggested, in the neonatal period LS may represent an ideal drug for immature myocardium characterized by a much more calcium dependent contractility than adults. Further studies are needed to evaluate the role of LS in refractory HF.

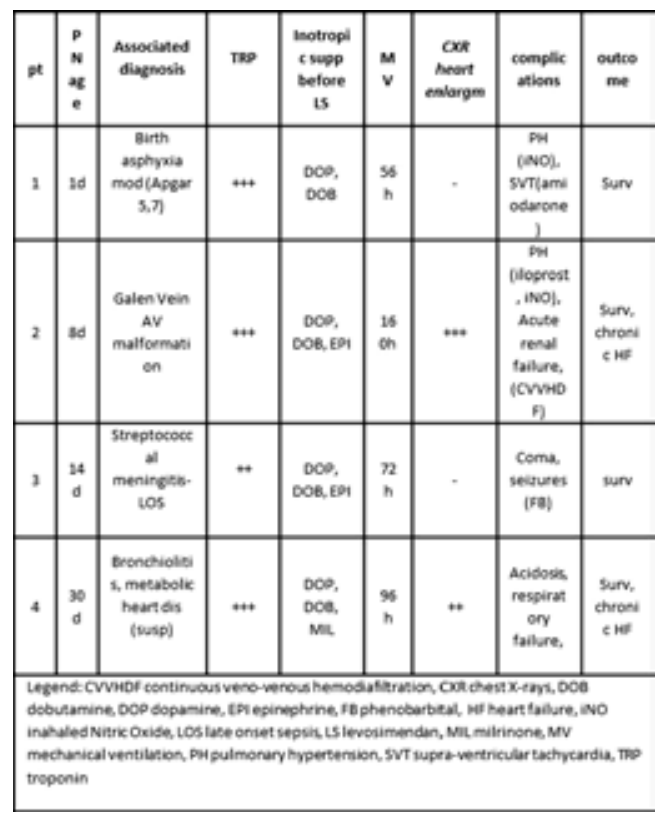

Abstract 1124 Figure 1 LS-neon 
1125 EFFICACY OF AN INDIVIDUALIZED STRATEGY FOR THE PHARMACOLOGICAL CLOSURE OF PDA WITH IBUPROFEN IN PRETERM INFANTS: EVALUATION BY ECHOCARDIOGRAPHY

doi:10.1136/archdischild-2012-302724.1125

S Galletti, A Cosentino, A Malavolti, E Machtey, G Faldella. Neonatology and Intensive Care Unit - Sant'Orsola-Malpighi Hospital - University of Bologna, Bologna, Italy

Background and Aims The aim of study is to evaluate the applicability of an individualized strategy for closure of PDA in preterms. We verified the closure rate and consequently the failure of PDA closure, the rate of reopening and the onset of secondary outcomes.

Methods We recruited 36 preterms (27 weeks mean GA; mean birth weight $828 \mathrm{~g}$ ) with PDA and candidates for the pharmacological closure according to the internal protocol.

Using serial ECHOS, we evaluated the persistence of the PDA after the administration of a first dose of ibuprofen, establishing the need to repeat a second or third dose each 24 hours.

Results We observed a rate of complete closure of $77.7 \%(33.3 \%$ after the first dose, $30.5 \%$ after the second and $13.8 \%$ after the third dose).

The incidence of re-opening is $16.6 \%$, without significant difference related to the number of doses $(\mathrm{p}=1)$.

There was a significant difference in terms of birth weight and GA between patients with persistent PDA (mean BW $485 \mathrm{~g}$ and mean GA 24+3) and patients who kept the ductus closed (mean BW $901.4 \mathrm{~g}$ and GA 27) $(\mathrm{p}<0.05)$.

There was no significant difference in terms of incidence of outcomes (IVH, NEC, broncodisplasia, deaths) comparing to a group which received a standard treatment of 3 doses.

Conclusion The individualized strategy allows to expose preterms to a minor amount of doses, without changing the number of closure and outcomes.

However, the extreme GA are associated with an increased risk of failure of closure and reopening.

\section{VITAMIN D LEVELS AND MYOCARDIAL FUNCTION IN PRETERM INFANTS}

doi:10.1136/archdischild-2012-302724.1126

1,2,3K Armstrong, ${ }^{4} \mathrm{C}$ Onwunmeme, ${ }^{5} \mathrm{O}$ Franklin, ${ }^{1,2,6 \mathrm{E}}$ Molloy. ${ }^{1}$ National Children's Research Centre, National Children's Research Centre; ${ }^{2}$ Neonatology, National Maternity Hospital; ${ }^{3}$ Cardiology, Our Lady's Children's Hospital; ${ }^{4}$ University College Dublin; ${ }^{5}$ Cardiology, Our Lady's Children's Hospital Crumlin Dublin 12; 'Paediatrics, University College Dublin, Dublin, Ireland

Bakground Low Vitamin D levels have been linked to cardiac failure in the adults and children. Tissue Doppler Imaging (TDI) is evolving as a superior measure of subtle changes in myocardial contractility in preterm infants. We aimed to correlate Vitamin D levels at birth with TDI measures of systolic and diastolic function.

Methods Preterm infants $<32$ weeks gestation were recruited. Vitamin D levels were measured at birth and echocardiography was carried out on Day 1. TDI myocardial velocities were recorded using a pulsed wave doppler sample from the lateral left/right ventricular wall \& intraventricular septum. Peak systolic (S'), early diastolic (E') and late diastolic $\left(\mathrm{A}^{\prime}\right)$ velocities were recorded.

Results Ten preterm infants with structurally normal hearts were recruited. Mean (SD) gestational age was 28 (1.7) weeks and birthweight $1.29(0.3) \mathrm{kg}$. There was no significant increase in Right ventricular systolic $(5.1 \mathrm{~cm} / \mathrm{sec}$ vs $4.8 \mathrm{~cm} / \mathrm{sec})$ or diastolic myocardial velocity measures $(5.2 \mathrm{~cm} / \mathrm{sec}$ vs $5.1 \mathrm{~cm} / \mathrm{sec})$ or left myocardial velocity systolic $(3.7 \mathrm{~cm} / \mathrm{sec}$ vs $3.9 \mathrm{~cm} / \mathrm{sec})$ or diastolic $(4.1 \mathrm{~cm} / \mathrm{sec}$ vs $4.0 \mathrm{~cm} / \mathrm{sec})$ measures between those with severe Vitamin $D$ deficiency $(<30 \mathrm{nmol} / \mathrm{L})$ and those with low normal levels of Vitamin D.
Conclusion Neonates with severe Vitamin D deficiency have similar TDI measures of systolic and diastolic velocity to those with near normal levels. In our small cohort severe Vitamin D deficiency appears to cause no impairment in myocardial contractility.

\section{MEASURING BLOOD PRESSURE AND MANAGING "HYPOTENSION" IN NEWBORN BABIES: VARIATION IN PRACTICES}

doi:10.1136/archdischild-2012-302724.1127

S Garg, W Tin. Neonatal Medicine, South Tees Hospitals NHS Foundation Trust, Middlesbrough, UK

Background and Aims Measuring blood pressure (BP) is an important part of cardiovascular assessment in newborns. Although arterial BP is considered as a gold standard, various methods of noninvasive $\mathrm{BP}$ measurements are used in clinical practice. The various studies have shown that BP measured by Doppler is better correlated with arterial BP than the oscillometric method. Regardless of definition of "hypotension", there is no agreement on its management strategies.

The Aim of this study is to survey the variations in practices in all tertiary neonatal units across England in management of hypotension.

Methods A structured questionnaire based telephonic survey.

Results The response rate was 100\% (45 units surveyed). Forty units (89\%) use arterial BP and/or oscillometric method, and only 5 units $(11 \%)$ use Doppler method. Twenty seven units (60\%) have written guidelines on management of hypotension. Forty $(90 \%)$ units use fluid bolus as the first line management; two units use fresh frozen plasma if the perfusion remains low. Thirty seven units $(82 \%)$ use dopamine as the first line inotropic agent. Twenty units (45\%) keep the umbilical arterial lines for as long as needed but the others keep them for different periods (3-14 days).

There are 9 different makes of oscillometric monitors used, and $10 \%$ of the units use different makes in one intensive care area.

Conclusion Marked variation remains in management of hypotension in newborn babies. There is a need to formulate evidence based guidelines for management of hypotension and to study the accuracy of non-invasive methods of BP measurement.

\section{EVALUATION OF ORAL PROSTAGLANDIN E1 IN MANAGEMENT OF DUCTUS DEPENDENT CONGENITAL HEART DISEASE}

doi:10.1136/archdischild-2012-302724.1128

${ }^{1}$ A Annagür, ${ }^{2 H}$ Altunhan, ${ }^{3} \mathrm{M}$ Konak, ${ }^{4} \mathrm{~S}$ Karaaslan, ${ }^{3} \mathrm{R}$ Örs. ${ }^{1}$ Selcuk University, Selcuklu Medical Faculty, Department of Neonatology; ${ }^{2}$ Abant Izzet Baysal University, Medical Faculty, Department of Neonatology; ${ }^{3}$ Konya University, Meram Medical Faculty, Department of Neonatology; ${ }^{4}$ Konya University, Meram Medical Faculty, Department of Cardiology, Konya, Turkey

Introduction Intravenous prostaglandin E1 (PGE1) infusion is a treatment which effect is proven in ductus dependent congenital heart disease. However, PGE1 is very expensive, needed continuous infusion and its supply is difficult by every center. When its long term use is necessary, these problems become more important.

Aim To show whether oral PGE1could keep the ductus open or not till the supply of intravenous PGE1.

Method Ten patients, who were admitted to newborn intensive care unit with the diagnosis of ductus dependent congenital heart disease and received oral PGE1 till the supply of intravenous PGE1, were evaluated.

Results It was observed that the $\mathrm{PO} 2$ and $\mathrm{SO} 2$ levels of patients measured 2 hours after the initiation of oral PGE1 were significantly increased compared to the levels before initiation of PGE1 $(p<0.05)$. It was also observed that the $\mathrm{PO} 2$ and $\mathrm{SO} 2$ levels of patients 